\title{
Forbidden Transitions in the Ground State Configuration of Doubly Ionized Argon
}

\author{
Leyla Özdemir, Selda Kabakçı, and İlker Armağan \\ Department of Physics, Sakarya University, 54187 Sakarya, Turkey \\ Correspondence should be addressed to Leyla Özdemir; lozdemir@sakarya.edu.tr
}

Received 24 October 2013; Revised 27 December 2013; Accepted 27 December 2013; Published 9 February 2014

Academic Editor: Predrag S. Krstic

Copyright (C) 2014 Leyla Özdemir et al. This is an open access article distributed under the Creative Commons Attribution License, which permits unrestricted use, distribution, and reproduction in any medium, provided the original work is properly cited.

We have calculated forbidden transitions (M1 and E2) between fine structure levels in the ground state configuration $3 s^{2} 3 \mathrm{p}^{4}$ of doubly ionized argon (Ar III) using the multiconfiguration Hartree-Fock approach within the framework of the Breit-Pauli Hamiltonian. The data for the analysis of forbidden lines in the spectrum is important for the study of the plasma in astrophysical objects and fusion devices. The results obtained from this work have been compared with other results available in the literature.

\section{Introduction}

Atomic radiative transition is one of the fundamental processes in plasmas. The numerical simulation of atomic kinetics in laboratory as well as astrophysical plasma requires accurate radiative transition rates [1]. Information about the term values and transition probabilities of highly stripped ions is required in astrophysics and plasma diagnostics. In plasma research, transitions in such ions can be used to determine temperature and density distributions. Forbidden transitions within the ground state configuration are particularly useful since their relatively long wavelengths make them convenient for spectroscopic studies [2]. Although the atomic kinetics depend on, in particular, optical allowed transitions (E1), the weak forbidden transitions (magnetic dipole, M1, and electric quadrupole, E2) have been linked to dominant features in the optical spectra of planetary nebulae and the aurora [3, 4]. Since the parity of upper and lower levels within the ground state configuration is the same, the electric dipole (E1) transitions are forbidden. The lowest-order metastable levels radiatively decay correspond to $\mathrm{M} 1$ and $\mathrm{E} 2$ transitions [5]. $\mathrm{M} 1$ and $\mathrm{E} 2$ transition rates are of several orders of magnitude smaller than those for E1 transitions with a similar energylevel separation.

Argon is one of the most abundant rare gases in the universe (its abundance is being $3.8 * 10^{-6}$ times smaller than that of hydrogen). Argon ion lines are observed in solar and astrophysical plasmas as well as in the laboratory [6]. The argon spectral lines are important in determining chemical abundances of elements and for estimation of the radiative transfer through stellar plasmas [7]. Argon plasma sources are required in various fields [8-11]. For this reason, the data on the transition parameters in multiply ionized argon ions is important for argon plasma modeling and laser physics $[12,13]$.

Some of the data for the energy levels and transition parameters on allowed and forbidden lines in Ar III can be found in NIST website [14]. M1 and E2 transition parameters for Ar III in NIST were compiled from the values reported by Czyak and Krueger [15], Naqvi [16], Bowen [17, 18], Kelly and Lacy [19], and Feuchtgruber et al. [20]. Saloman and Kim calculated magnetic dipole and electric quadrupole transition rates for S-like ions between ground state terms using multiconfiguration Dirac-Fock wave functions [2] . Calamai and Johnson measured the natural lifetimes of the $\mathrm{ns}^{2} \mathrm{np}^{4}\left({ }^{1} \mathrm{~S}_{0}\right)$ metastable states for some rare gases $\left(\mathrm{Ar}^{2+}, \mathrm{Kr}^{2+}\right.$, and $\left.\mathrm{Xe}^{2+}\right)$ using an ion trapping technique [21]. Biémont and Hansen calculated energy levels and radiative transition probabilities in the ground configurations of the sulfur and selenium isoelectronic sequences up to molybdenum and silver, respectively, using HFR self-consistent method [22]. Prior observed M1 and E2 lines from trapped metastable Ar III and $\mathrm{Cu}$ II ions [23]. Mendoza and Zeippen calculated radiative transition probabilities for the forbidden lines in 
the ground configuration of all the members of the sulfur isoelectronic sequence [24]. Fine structure splitting in Ar III was calculated using the $R$-matrix method by Stancalie et al. [6]. Träbert discussed some examples of measurements and calculations of the radiative lifetime of the $n \mathrm{n}^{41} \mathrm{~S}_{0}$ level in $\mathrm{Ne}^{2+}, \mathrm{Ar}^{2+}, \mathrm{Kr}^{2+}$, and $\mathrm{Xe}^{2+}$ ions [25]. Pasternack reported the transition probabilities of forbidden lines for atoms in the $\mathrm{p}^{2}, \mathrm{p}^{3}, \mathrm{p}^{4}, \mathrm{~d}^{2}$, and $\mathrm{d}^{3}$ configurations $[26,27]$. Burger et al. presented 38 Ar III and 14 Ar IV A values obtained on the basis of the relative line intensity ratio method in the wavelength interval between $240 \mathrm{~nm}$ and $308 \mathrm{~nm}$ [7]. The weighted oscillator strengths (gf) and the lifetimes for Ar III were presented using a multiconfiguration Hartree-Fock relativistic (HFR) approach by Luna et al. [28]. Nandi et al. presented a comprehensive analysis of beam-foil and beamgas excited spectrum of argon observed in small wavelength region, 2965-3090 $\AA$, using $\mathrm{Ar}^{+}$and $\mathrm{Ar}^{2+}$ ions in the energy range $200-650 \mathrm{keV}$ [29]. Ultraviolet and visible spectra of the symbiotic nova RR Telescopii were used to derive reference wavelengths for many forbidden and intercombination transitions of ions +1 to +6 of elements $\mathrm{C}, \mathrm{N}, \mathrm{O}, \mathrm{Ne}, \mathrm{Na}, \mathrm{Mg}, \mathrm{Al}, \mathrm{Si}$, $\mathrm{P}, \mathrm{S}, \mathrm{Cl}, \mathrm{Ar}, \mathrm{K}$, and Ca by Young et al. [30]. The transition probabilities of spontaneous emission of eight transitions in Ar III and seventeen transitions in Ar IV spectrum were obtained using the relative line intensity ratios method by Djeniže and Bukvić [31]. The radiative lifetime of the $3 \mathrm{~s}^{2} 3 \mathrm{p}^{4}{ }^{1} \mathrm{~S}_{0}$ level in $\mathrm{Ar}^{2+}$ ions was measured via time resolved observation of the magnetic dipole (M1) transition to the $n s^{2} \mathrm{np}^{4}{ }^{3} \mathrm{P}_{1}$ level, on ions circulating in a heavy-ion storage ring by Träbert and Gwinner [5]. Fischer et al. investigated the fine structure levels of $3 \mathrm{~s}^{2} 3 \mathrm{p}^{3} 3 \mathrm{~d}^{3} \mathrm{D}$ for Ar III using nonorthogonal spline CI, multiconfiguration Hartree-Fock (MCHF), and multiconfiguration Dirac-Hartree-Fock (MCDHF) methods [32]. Theoretical energy levels and transition probabilities were presented for 47 low-lying levels of sulfur-like ions for all $Z \geq 18$ using the multiconfiguration Dirac-Fock method by Chou et al. [33]. Using a compilation of experimental energy levels, Verner et al. derived accurate wavelengths for 5599 lines of 1828 ground-term multiplets $g f$-values calculated in the Opacity Project and they recalculated the Opacity Project multiplet $g f$-values to oscillator strengths and transition probabilities of individual lines [34]. The energy levels and observed spectral lines of ionized argon atoms in all stages of ionization were presented by Saloman [35]. Johnson and Kingston calculated collision strengths for electron excitation of the $3 \mathrm{~s}^{2} 3 \mathrm{p}^{4}$ levels of Ar III using the $R$-matrix method [36]. Munoz Burgos et al. calculated electron-impact excitation of $\mathrm{Ar}^{2+}$ including excitation up to the $5 \mathrm{~s}$ subshell using $R$-matrix method [37].

The aim of this work is to investigate the forbidden transitions (M1 and E2) between energy levels within the ground state configuration of doubly ionized argon (Ar III) using multiconfiguration Hartree-Fock approach within the framework of Breit-Pauli Hamiltonian [38]. We have obtained the M1 and E2 transition parameters such as transition energies, line strengths, and transition probabilities (or rates) using the MCHF atomic structure code [39]. Although $\mathrm{Ar}$ is not a heavy element, the relativistic contributions to the wave functions and energies of levels must be involved. Also an accurate atomic structure via large configuration interaction (CI) basis is required. Therefore, our calculations include the relativistic contributions and correlation effects. For considering the correlation effects in this work, the configurations of $3 s^{2} 3 p^{4}, 3 p^{6}, 3 s^{2} 3 p^{3} 4 p, 3 p^{5} 4 p, 3 s 3 p^{4} 3 d$, $3 s^{2} 3 p^{2} 3 d^{2}$, and $3 p^{4} 3 d^{2}$ have been considered.

\section{Calculation Method}

Radiative properties of atoms are described with an electromagnetic transition between two states which is characterized by the angular momentum and parity of the corresponding photon. They are very useful in the fields of quantum electronic, atomic physics and laser spectroscopy, plasma physics, and astrophysics. Hence, the reliability of the values of these parameters is mainly based on the performance of the calculation methods used. A detail of theoretical background can be found in the literature $[38,39]$. We have here presented some formulas. Briefly, if the emitted or observed photon has angular momentum $k$ and parity $\pi=(-1)^{k}$, the transition is an electric multipole transition (Ek), while the transition from absorbed photon with parity $\pi=(-1)^{k+1}$ is magnetic multipole transition (Mk).

The transition probability for the emission from the upper level to the lower level is given by

$$
A^{\pi k}\left(\gamma^{\prime} J^{\prime}, \gamma J\right)=2 C_{k}\left[\alpha\left(E_{\gamma^{\prime} J^{\prime}}-E_{\gamma J}\right)\right]^{2 k+1} \frac{S^{\pi k}\left(\gamma^{\prime} J^{\prime}, \gamma J\right)}{g_{J^{\prime}}},
$$

where $S^{\pi k}$ is line strength,

$$
S^{\pi k}\left(\gamma^{\prime} J^{\prime}, \gamma J\right)=\left|\left\langle\gamma J\left\|\mathbf{O}^{\pi(k)}\right\| \gamma^{\prime} J^{\prime}\right\rangle\right|^{2},
$$

$C_{k}=(2 k+1)(k+1) / k((2 k+1) ! !)^{2}$, and $\mathbf{O}^{\pi(k)}$ is transition operator. The transition rates (or probabilities) for forbidden transitions depend on the third (in M1 transition) or fifth (in E2 transition) power of transition energy.

\section{Results and Discussion}

In this work, the transition energies, line strengths, and transition probabilities (or rates) for forbidden transitions (magnetic dipole, M1, and electric quadrupole, E2) between the levels in the ground state configuration for doubly ionized argon (Ar III) have been calculated using the multiconfiguration Hartree-Fock atomic structure code [39] based on the multiconfiguration Hartree-Fock approach within the Breit-Pauli relativistic corrections [38]. In the calculations, the configurations of $3 s^{2} 3 p^{4}, 3 p^{6}, 3 s^{2} 3 p^{3} 4 p, 3 p^{5} 4 p, 3 s 3 p^{4} 3 d$, $3 s^{2} 3 p^{2} 3 d^{2}$, and $3 p^{4} 3 d^{2}$ are included due to considering correlation effects. Table 1 displays the results including transition energies, line strengths, and transition probabilities (or rates) for M1 and E2 transitions in the ground state configuration $[\mathrm{Ne}] 3 \mathrm{~s}^{2} 3 \mathrm{p}^{4}$. In table, we have omitted the core and have only given the levels excited of $3 s^{2} 3 p^{4}$. 
TABLE 1: Transition energies, $\Delta E\left(\mathrm{~cm}^{-1}\right)$, line strengths, $S$ (a.u.), and transition probabilities, $A_{\mathrm{ki}}\left(\mathrm{s}^{-1}\right)$, for forbidden transitions (M1 and E2) of the ground state $3 \mathrm{~s}^{2} 3 \mathrm{p}^{4}$ configuration for Ar III. In table, $a(b)$ denotes $a \times 10^{b}$.

\begin{tabular}{|c|c|c|c|c|c|c|}
\hline \multirow{2}{*}{ Transitions } & \multicolumn{2}{|c|}{$\Delta E$} & \multicolumn{2}{|c|}{$S$} & \multicolumn{2}{|c|}{$A_{\mathrm{ki}}$} \\
\hline & This work & Other works & This work & Other works & This work & Other works \\
\hline \multicolumn{7}{|c|}{ M1 transitions } \\
\hline${ }^{3} \mathrm{P}_{1}-{ }^{1} \mathrm{~S}_{0}$ & 33734.36 & $\begin{array}{c}32153.53^{\mathrm{a}} \\
32135^{\mathrm{d}} \\
32155^{\mathrm{e}} \\
30688^{\mathrm{g}} \\
30122.89^{\mathrm{h}}\end{array}$ & $3.36(-3)$ & $4.48(-3)^{\mathrm{a}}$ & 3.48 & $\begin{array}{c}4.02^{\mathrm{a}} \\
3.972^{\mathrm{d}} \\
3.91^{\mathrm{f}}\end{array}$ \\
\hline${ }^{3} \mathrm{P}_{2}-{ }^{-1} \mathrm{D}_{2}$ & - & $\begin{array}{c}14010.0^{\mathrm{a}} \\
13972^{\mathrm{d}} \\
14010^{\mathrm{e}} \\
17305.26^{\mathrm{g}} \\
16328.91^{\mathrm{h}}\end{array}$ & - & $2.16(-3)^{\mathrm{a}}$ & - & $\begin{array}{l}3.21(-2)^{\mathrm{a}} \\
4.5(-1)^{\mathrm{b}} \\
3.2(-1)^{\mathrm{c}} \\
3.23(-1)^{\mathrm{d}} \\
3.13(-1)^{\mathrm{f}}\end{array}$ \\
\hline${ }^{3} \mathrm{P}_{1}-{ }^{1} \mathrm{D}_{2}$ & 14914.19 & $\begin{array}{c}12897.83^{\mathrm{a}} \\
12865^{\mathrm{d}} \\
12898^{\mathrm{e}} \\
17647.36^{\mathrm{g}} \\
15275.43^{\mathrm{h}}\end{array}$ & $4.70(-3)$ & $7.2(-3)^{\mathrm{a}}$ & $8.41(-2)$ & $\begin{array}{l}8.3(-2)^{\mathrm{a}} \\
12(-2)^{\mathrm{b}} \\
8.5(-2)^{\mathrm{c}} \\
8.43(-2)^{\mathrm{d}} \\
8.22(-2)^{\mathrm{f}}\end{array}$ \\
\hline${ }^{3} \mathrm{P}_{2}-{ }^{3} \mathrm{P}_{1}$ & 1008.28 & $\begin{array}{c}1112.17^{\mathrm{a}} \\
1107^{\mathrm{d}} \\
1112^{\mathrm{e}} \\
1131.74^{\mathrm{g}} \\
1053.41^{\mathrm{h}}\end{array}$ & 2.50 & $2.50^{\mathrm{a}}$ & $2.30(-2)$ & $\begin{array}{c}3.1(-2)^{\mathrm{a}} \\
3.1(-2)^{\mathrm{c}} \\
3.054(-2)^{\mathrm{d}} \\
3.08(-2)^{\mathrm{f}}\end{array}$ \\
\hline${ }^{3} \mathrm{P}_{1}-{ }^{3} \mathrm{P}_{0}$ & 428.35 & $\begin{array}{c}458.06^{\mathrm{a}} \\
463^{\mathrm{d}} \\
458^{\mathrm{e}} \\
468.96^{\mathrm{g}} \\
449.92^{\mathrm{h}} \\
\end{array}$ & 2.00 & $2.00^{\mathrm{a}}$ & $4.23(-3)$ & $\begin{array}{c}5.19(-3)^{\mathrm{a}} \\
5.2(-3)^{\mathrm{c}} \\
5.354(-3)^{\mathrm{d}} \\
5.17(-3)^{\mathrm{f}}\end{array}$ \\
\hline \multicolumn{7}{|c|}{ E2 transitions } \\
\hline${ }^{3} \mathrm{P}_{2}-{ }^{1} \mathrm{~S}_{0}$ & 34742.64 & $\begin{array}{c}33265.7^{\mathrm{a}} \\
33242^{\mathrm{d}} \\
33267^{\mathrm{e}} \\
31819.69^{\mathrm{g}} \\
31176.37^{\mathrm{h}}\end{array}$ & $4.46(-3)$ & $9.4(-3)^{\mathrm{a}}$ & $2.53(-2)$ & $\begin{array}{c}4.3(-2)^{\mathrm{a}} \\
3.493(-2)^{\mathrm{d}} \\
4.17(-2)^{\mathrm{f}}\end{array}$ \\
\hline${ }^{1} \mathrm{D}_{2}-{ }^{1} \mathrm{~S}_{0}$ & 18820.16 & $\begin{array}{c}19255.7^{\mathrm{a}} \\
19271^{\mathrm{d}} \\
19257^{\mathrm{e}} \\
14514.43^{\mathrm{g}} \\
14847.46^{\mathrm{h}}\end{array}$ & $0.87(1)$ & $1.05(1)^{\mathrm{a}}$ & 2.30 & $\begin{array}{c}3.10^{\mathrm{a}} \\
2.693^{\mathrm{d}} \\
2.59^{\mathrm{f}}\end{array}$ \\
\hline${ }^{3} \mathrm{P}_{2}-{ }^{1} \mathrm{D}_{2}$ & - & $\begin{array}{c}14010.0^{\mathrm{a}} \\
13972^{\mathrm{d}} \\
14010^{\mathrm{e}} \\
16328.91^{\mathrm{h}}\end{array}$ & - & $1.2(-1)^{\mathrm{a}}$ & - & $\begin{array}{c}1.4(-3)^{\mathrm{a}} \\
2.9(-3)^{\mathrm{c}} \\
1.362(-3)^{\mathrm{d}} \\
1.14(-3)^{\mathrm{f}}\end{array}$ \\
\hline${ }^{3} \mathrm{P}_{1^{-}}{ }^{1} \mathrm{D}_{2}$ & 14914.19 & $\begin{array}{c}12897.83^{\mathrm{a}} \\
12865^{\mathrm{d}} \\
12898^{\mathrm{e}} \\
15704.55^{\mathrm{g}} \\
15275.43^{\mathrm{h}}\end{array}$ & $1.08(-2)$ & $1.6(-2)^{\mathrm{a}}$ & $1.78(-4)$ & $\begin{array}{c}1.3(-4)^{\mathrm{a}} \\
2.7(-4)^{\mathrm{c}} \\
1.349(-4)^{\mathrm{d}} \\
1.14(-4)^{\mathrm{f}}\end{array}$ \\
\hline${ }^{3} \mathrm{P}_{0}-{ }^{1} \mathrm{D}_{2}$ & 14485.85 & $\begin{array}{c}12439.77^{\mathrm{a}} \\
12402^{\mathrm{d}} \\
12440^{\mathrm{e}} \\
14825.51^{\mathrm{h}}\end{array}$ & $3.17(-3)$ & $4.3(-3)^{\mathrm{a}}$ & $4.52(-5)$ & $\begin{array}{c}2.9(-5)^{\mathrm{a}} \\
7.0(-5)^{\mathrm{b}} \\
5.8(-5)^{\mathrm{c}} \\
2.038(-5)^{\mathrm{d}} \\
2.21(-5)^{\mathrm{f}}\end{array}$ \\
\hline
\end{tabular}


TABle 1: Continued.

\begin{tabular}{|c|c|c|c|c|c|c|}
\hline \multirow{2}{*}{ Transitions } & \multicolumn{2}{|c|}{$\Delta E$} & \multicolumn{2}{|c|}{$S$} & \multicolumn{2}{|c|}{$A_{\mathrm{ki}}$} \\
\hline & This work & Other works & This work & Other works & This work & Other works \\
\hline${ }^{3} \mathrm{P}_{2}-{ }^{3} \mathrm{P}_{0}$ & 1436.63 & $\begin{array}{c}1570.23^{\mathrm{a}} \\
1570^{\mathrm{d}} \\
1570^{\mathrm{e}} \\
1600.70^{\mathrm{g}} \\
1503.41^{\mathrm{h}}\end{array}$ & 2.46 & $2.54^{\mathrm{a}}$ & $1.69(-6)$ & $\begin{array}{c}2.72(-6)^{\mathrm{a}} \\
5.6(-5)^{\mathrm{c}} \\
2.784(-6)^{\mathrm{d}} \\
2.37(-6)^{\mathrm{f}}\end{array}$ \\
\hline${ }^{3} \mathrm{P}_{2}-{ }^{3} \mathrm{P}_{1}$ & 1008.28 & $\begin{array}{c}1112.17^{\mathrm{a}} \\
1107^{\mathrm{d}} \\
1112^{\mathrm{e}} \\
1131.74^{\mathrm{g}} \\
1053.48^{\mathrm{h}}\end{array}$ & 5.50 & $5.7^{\mathrm{a}}$ & $2.14(-7)$ & $\begin{array}{c}3.6(-7)^{\mathrm{a}} \\
7.4(-7)^{\mathrm{c}} \\
3.617(-7)^{\mathrm{d}} \\
3.13(-7)^{\mathrm{f}}\end{array}$ \\
\hline
\end{tabular}

${ }^{\mathrm{a}}$ Ref. [14], ${ }^{\mathrm{b}}$ Ref. [27], ${ }^{\mathrm{c}}$ Ref. [26], ${ }^{\mathrm{d}}$ Ref. [22], ${ }^{\mathrm{e}}$ Ref. [40], ${ }^{\mathrm{f}}$ Ref. [24], ${ }^{\mathrm{g}}$ Ref. [6], and ${ }^{\mathrm{h}}$ Ref. [37].

The results obtained from this work are generally in agreement with other works. In M1 transitions, the transition energies for ${ }^{3} \mathrm{P}_{1}-{ }^{1} \mathrm{D}_{2},{ }^{3} \mathrm{P}_{2}-{ }^{3} \mathrm{P}_{1}$, and ${ }^{3} \mathrm{P}_{1}-{ }^{3} \mathrm{P}_{0}$ are in agreement with the values reported in [37]. ${ }^{3} \mathrm{P}_{1^{-}}{ }^{1} \mathrm{~S}_{0}$ transition energy is in agreement with $[14,22,40]$. We have compared our line strength values with those in NIST [14]. Only the line strength for ${ }^{3} \mathrm{P}_{1^{-}}{ }^{1} \mathrm{D}_{2}$ transition is somewhat poor. There is also good agreement in transition probabilities. In E2 transitions, the transition energies for ${ }^{3} \mathrm{P}_{2}-{ }^{1} \mathrm{~S}_{0},{ }^{1} \mathrm{D}_{2}-{ }^{1} \mathrm{~S}_{0},{ }^{3} \mathrm{P}_{1}{ }^{-1} \mathrm{D}_{2},{ }^{3} \mathrm{P}_{0^{-}}{ }^{1} \mathrm{D}_{2}$, ${ }^{3} \mathrm{P}_{2}-{ }^{3} \mathrm{P}_{0}$, and ${ }^{3} \mathrm{P}_{2}-{ }^{3} \mathrm{P}_{1}$ are in good agreement with $[6,14,22$, 37]. The line strengths are also in agreement with the values of NIST. Moreover, the transition probabilities for this transition type are in agreement with other works. It is noted that the values reported by Pasternack within the other works are somewhat poor. It is seen in first column that there is no values for M1 transition of ${ }^{3} \mathrm{P}_{2}{ }^{-}{ }^{1} \mathrm{D}_{2}$ and $\mathrm{E} 2$ transition of ${ }^{3} \mathrm{P}_{2}$ ${ }^{1} \mathrm{D}_{2}$. We have not obtained these transitions in this work due to the forbiddenness of $J-J^{\prime}=0$ transitions in this computer code.

In conclusion, the aim of this work is to investigate the transitions between excited levels of ground state configuration in doubly ionized argon (Ar III) using the approach within the framework of the Breit-Pauli Hamiltonian. Such excited states, known as metastable states, perform weak spectral lines, and they decay via magnetic dipole (M1) and electric quadrupole (E2) transitions. The values for transition energies, line strengths, and transition probabilities are fundamental quantities for many scientific applications. Especially, forbidden transitions such as M1 and E2 are of great interest for plasma diagnostics and modeling. Therefore, we hope that our results on $\mathrm{M} 1$ and $\mathrm{E} 2$ transitions in Ar III will provide the supports to further researches for this ion.

\section{Conflict of Interests}

The authors declare that there is no conflict of interests regarding the publication of this paper.

\section{Acknowledgments}

The authors are very grateful to the anonymous reviewers for stimulating comments and valuable suggestions, which resulted in improvements to this paper.

\section{References}

[1] Y. Zou and C. F. Fischer, "Multiconfiguration Dirac-HartreeFock calculations of the forbidden transitions between ${ }^{3} \mathrm{~s}^{2}{ }^{1} \mathrm{~S}_{0}$, $3 \mathrm{~s} 3 \mathrm{p}^{3} \mathrm{P}_{0,1,2},{ }^{1} \mathrm{P}_{1}$ states for Mg-like ions," Journal of Physics $B$, vol. 34, no. 5, pp. 915-931, 2001.

[2] E. B. Saloman and Y.-K. Kim, "Effects of configuration mixing in $\mathrm{M} 1$ and E2 transitions between ground-state terms of sulfurlike ions," Physical Review A, vol. 38, no. 2, pp. 577-583, 1988.

[3] E. Träbert, "Atomic lifetime measurements with ion traps of many sizes," Physica Scripta, vol. 61, no. 3, pp. 257-286, 2000.

[4] I. Bowen, Reviews of Modern Physics, vol. 8, no. 5, pp. 55-81, 1936.

[5] E. Träbert and G. Gwinner, "(M1 + E2) decay rate in $\mathrm{Ar}^{2+}$ ions measured at a heavy-ion storage ring," Physical Review A, vol. 65, no. 1, Article ID 014501, 4 pages, 2001.

[6] V. Stancalie, V. F. Pais, and A. Mihailescu, "Fine-structure splitting calculation in the Ar III ion: comparison of perturbative (Breit-Pauli) and non-perturbative (MCDF-EAL) predictions," European Physical Journal D, vol. 66, no. 3, Article ID 20665, 15 pages, 2012.

[7] M. Burger, M. Skočić, M. Gavrilov, S. Bukvić, and S. Djeniže, "Experimental transition probabilities in the Ar III and Ar IV UV spectra," Journal of Quantitative Spectroscopy \& Radiative Transfer, vol. 113, no. 13, pp. 1662-1688, 2012.

[8] M. Celik, "Spectral measurements of inductively coupled and helicon discharge modes of a laboratory argon plasma source," Spectrochimica Acta B, vol. 66, no. 2, pp. 149-155, 2011.

[9] G. Lotito, T. Nelis, P. Guillot, and D. Günther, "Characterization of argon metastable species as function of time, space, and current of a pulsed dc glow discharge," Spectrochimica Acta B, vol. 66, no. 8, pp. 619-626, 2011.

[10] Q. L. Ma, V. Motto-Ros, W. Q. Lei et al., "Temporal and spatial dynamics of laser-induced aluminum plasma in argon background at atmospheric pressure: interplay with the ambient gas," Spectrochimica Acta B, vol. 65, no. 11, pp. 896-907, 2010. 
[11] G. Kühn, F. Könemann, and M. Kock, "The role of Ar III in quantitative spectroscopy on hot argon plasmas," Journal of Quantitative Spectroscopy and Radiative Transfer, vol. 105, no. 1, pp. 102-110, 2007.

[12] W. B. Bridges and A. N. Chester, "Visible and UV laser oscillation at 118 wavelengths in ionized neon, argon, krypton, xenon, oxygen and other gases," Applied Optics, vol. 4, no. 1, pp. 573-580, 1965.

[13] P. K. Cheo and H. G. Cooper, "Ultraviolet ion laser transitions between 2300 and 4000 Å," Journal of Applied Physics, vol. 36, no. 6, pp. 1862-1865, 1965.

[14] NIST, http://physics.nist.gov/asd3.

[15] S. J. Czyak and T. K. Krueger, "Forbidden transition probabilities for some P, S, Cl, and Ar ions," Monthly Notices of the Royal Astronomical Society, vol. 126, pp. 177-194, 1963.

[16] A. M. Naqvi, Mutual magnetic interaction in p-electron configurations (with calculations of transition probabilities and astrophysical applications) [Ph.D. thesis], Harvard University, 1951.

[17] I. S. Bowen, "Wave lengths of forbidden nebular lines II," Astrophysical Journal, vol. 132, no. 1, pp. 1-17, 1960.

[18] I. I. Bowen, "Wave lengths of forbidden nebular lines," Astrophysical Journal, vol. 121, no. 6, pp. 306-311, 1955.

[19] D. M. Kelly and J. H. Lacy, "Accurate wavenumbers for midinfrared fine-structure lines," Astrophysical Journal Letters, vol. 454, no. 2, pp. L161-L164, 1995.

[20] H. Feuchtgruber, D. Lutz, and D. A. Beintema, "New rest wavelength determinations for seven mid-infrared fine-structure lines by ISO-SWS," Astrophysical Journal, vol. 136, no. 1, pp. 221224, 2001

[21] A. G. Calamai and C. E. Johnson, "Radiative lifetimes of several metastable states of doubly and triply ionized Ar, Kr, and Xe," Physical Review A, vol. 45, no. 11, pp. 7792-7799, 1992.

[22] E. Biémont and J. E. Hansen, "Forbidden transitions in $3 \mathrm{p}^{4}$ and $4 \mathrm{p}^{4}$ configurations," Physica Scripta, vol. 34, no. 2, pp. 116-130, 1986.

[23] M. H. Prior, "Radiative decay rates of metastable Ar III and $\mathrm{Cu}$ II ions," Physical Review A, vol. 30, no. 6, pp. 3051-3056, 1984.

[24] C. Mendoza and C. J. Zeippen, "Transition probabilities for forbidden lines in the $3 \mathrm{p}^{4}$ configuration, III," Monthly Notices of the Royal Astronomical Society, vol. 202, pp. 981-986, 1983.

[25] E. Träbert, "Level lifetimes dominated by electric-dipole forbidden decay rates in the ground configuration of doubly charged rare gas ions $\left(\mathrm{Ne}^{2+}, \mathrm{Ar}^{2+}, \mathrm{Kr}^{2+}\right.$ and $\left.\mathrm{Xe}^{2+}\right)$," Physica Scripta, vol. 85, no. 4, Article ID 048101, 6 pages, 2012.

[26] S. Pasternack, "Transition probabilities of forbidden lines," Astrophysical Journal, vol. 92, no. 2, pp. 129-155, 1940.

[27] S. Pasternack, "Transition probabilities for some forbidden lines of astrophysical interest," Publications of the Astronomical Society of the Pacific, vol. 51, pp. 160-162, 1939.

[28] F. R. T. Luna, F. Bredice, G. H. Cavalcanti, and A. G. Trigueiros, "Weighted oscillator strengths and lifetimes for the Ar III spectrum," Journal of Quantitative Spectroscopy and Radiative Transfer, vol. 69, no. 2, pp. 171-188, 2001.

[29] T. Nandi, A. P. Mishra, and B. N. Jagatap, "Observation of transitions involving core-excited states in Ar III and Ar IV and high-lying singly excited states in Ar I-Ar IV," Journal of Quantitative Spectroscopy and Radiative Transfer, vol. 112, no. 18, pp. 2771-2778, 2011.

[30] P. R. Young, U. Feldman, and A. Lobel, "Forbidden and intercombination lines of RR Telescopii: wavelength measurements and energy levels," Astrophysical Journal, vol. 196, no. 2, article 23, 2011.

[31] S. Djeniže and S. Bukvić, "Transition probabilities of several transitions in the Ar III and Ar IV spectra," Astronomy \& Astrophysics, vol. 365, no. 2, pp. 252-257, 2001.

[32] C. F. Fischer, G. Tachiev, and A. Irimia, "Relativistic energy levels, lifetimes, and transition probabilities for the sodium-like to argon-like sequences," Atomic Data and Nuclear Data Tables, vol. 92, no. 5, pp. 607-812, 2006.

[33] H.-S. Chou, J.-Y. Chang, Y.-H. Chang, and K.-N. Huang, "Energy-level scheme and transition probabilities of S-like ions," Atomic Data and Nuclear Data Tables, vol. 62, no. 1, pp. 77-145, 1996.

[34] D. A. Verner, E. M. Verner, and G. J. Ferland, "Atomic data for permitted resonance lines of atoms and ions from $\mathrm{H}$ to $\mathrm{Si}$, and S, Ar, Ca, and Fe," Atomic Data and Nuclear Data Tables, vol. 64, no. 1, pp. 1-180, 1996.

[35] E. B. Saloman, "energy levels and observed spectral lines of ionized argon, Ar II through Ar XVIII," Journal of Physical and Chemical Reference Data, vol. 39, no. 3, Article ID 033101, 163 pages, 2010.

[36] C. T. Johnson and A. E. Kingston, "Electron impact excitation of the $3 \mathrm{~s}^{2} 3 \mathrm{p}^{4}$ levels of Ar III," Journal of Physics B, vol. 23, no. 19, pp. 3393-3405, 1990.

[37] J. M. Munoz Burgos, S. D. Loch, C. P. Ballance, and R. F. Boivin, "Electron-impact excitation of $\mathrm{Ar}^{2+}$," Astronomy and Astrophysics, vol. 500, no. 3, pp. 1253-1261, 2009.

[38] C. F. Fischer, T. Brage, and P. Jönsson, Computational Atomic Structure-An MCHF Approach, Institute of Physics Publishing, Philadelphia, Pa, USA, 1997.

[39] C. F. Fischer, "MCHF atomic-structure package," Computer Physics Communications, vol. 128, no. 3, pp. 635-636, 2000.

[40] C. E. Moore, Atomic Energy Levels as Derived from the Analyses of Optical Spectra, vol. 467 of National Bureau of Standards Circular, U.S. Department of Commerce, National Bureau of Standards, Washington, DC, USA, 1949. 

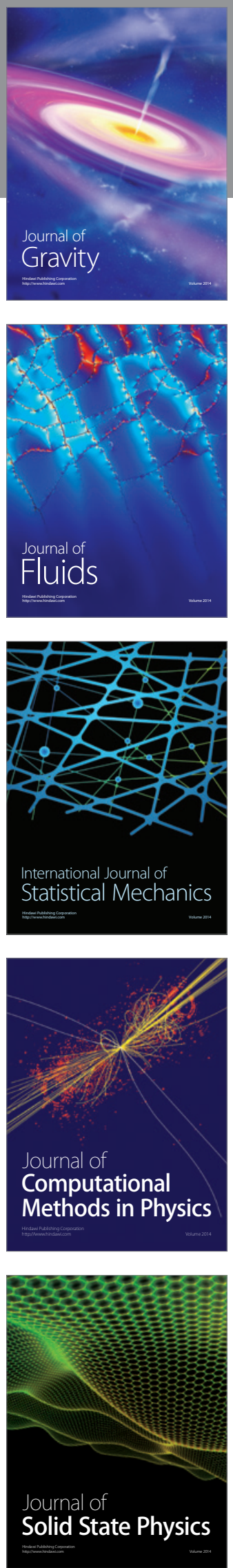

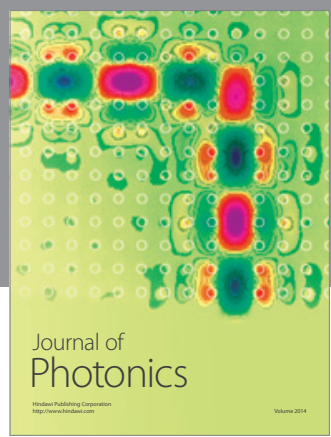

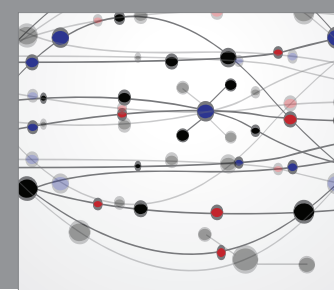

The Scientific World Journal

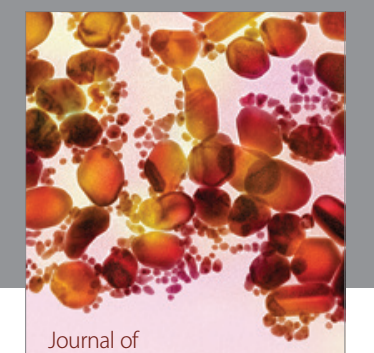

Soft Matter
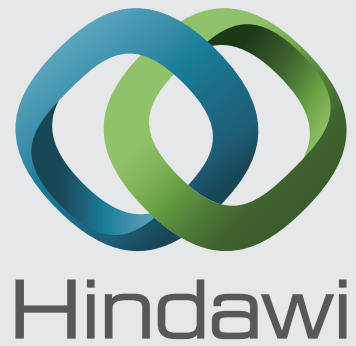

Submit your manuscripts at

http://www.hindawi.com
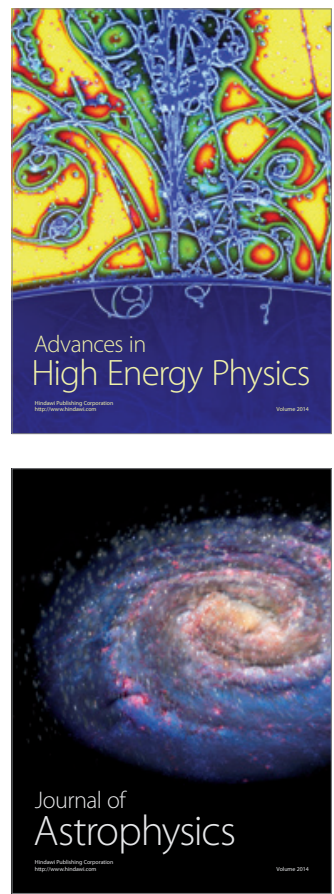
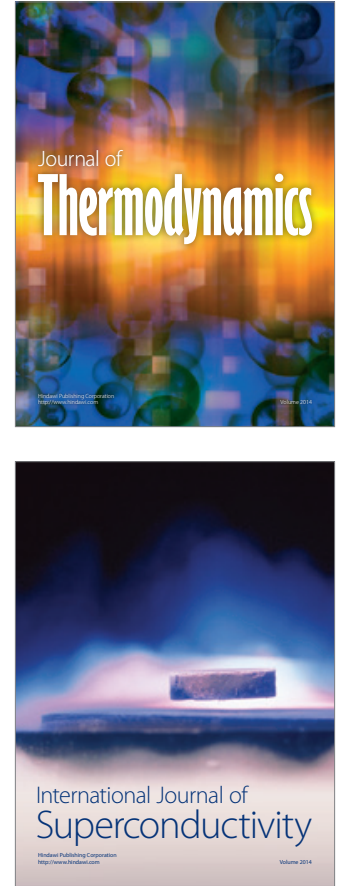
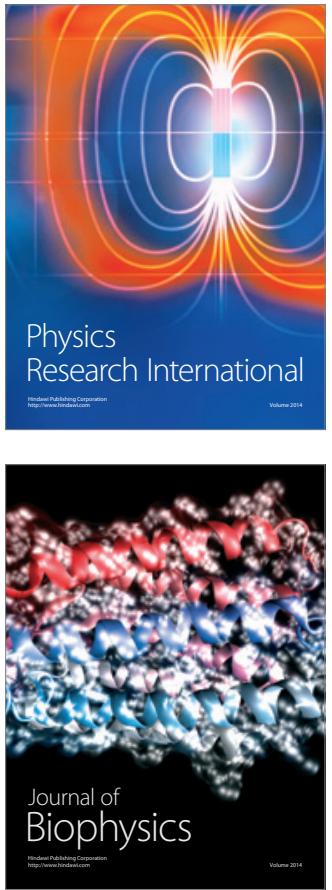
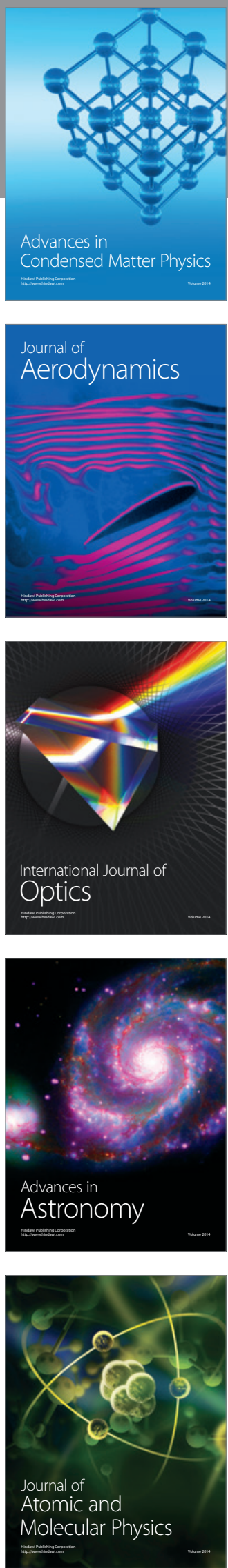